\title{
The epistatic interaction between the dopamine D3 receptor and dysbindin-1 modulates higher-order cognitive functions in mice and humans
}

\author{
G. M. Leggio ${ }^{1} \cdot$ S. A. Torrisi ${ }^{1} \cdot$ R. Mastrogiacomo ${ }^{2} \cdot$ D. Mauro ${ }^{2} \cdot$ M. Chisari ${ }^{1} \cdot$ C. Devroye ${ }^{2} \cdot$ D. Scheggia $\mathbb{C}^{2} \cdot$ M. Nigro $^{2}$. \\ F. Geraci ${ }^{1} \cdot$ N. Pintori ${ }^{3} \cdot$ G. Giurdanella ${ }^{1} \cdot$ L. Costa $^{4}{ }^{4} \cdot$ C. Bucolo ${ }^{1} \cdot$ V. Ferretti ${ }^{2} \cdot$ M. A. Sortino ${ }^{1} \cdot$ L. Ciranna $^{1}$. $^{2}$

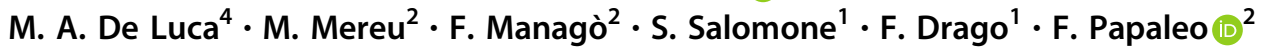

Received: 18 May 2018 / Revised: 15 July 2019 / Accepted: 26 July 2019

(C) The Author(s), under exclusive licence to Springer Nature Limited 2019

\begin{abstract}
The dopamine D2 and D3 receptors are implicated in schizophrenia and its pharmacological treatments. These receptors undergo intracellular trafficking processes that are modulated by dysbindin-1 (Dys). Indeed, Dys variants alter cognitive responses to antipsychotic drugs through D2-mediated mechanisms. However, the mechanism by which Dys might selectively interfere with the D3 receptor subtype is unknown. Here, we revealed an interaction between functional genetic variants altering Dys and D3. Specifically, both in patients with schizophrenia and in genetically modified mice, concomitant reduction in D3 and Dys functionality was associated with improved executive and working memory abilities. This D3/Dys interaction produced a D2/D3 imbalance favoring increased D2 signaling in the prefrontal cortex (PFC) but not in the striatum. No epistatic effects on the clinical positive and negative syndrome scale (PANSS) scores were evident, while only marginal effects on sensorimotor gating, locomotor functions, and social behavior were observed in mice. This genetic interaction between D3 and Dys suggests the D2/D3 imbalance in the PFC as a target for patient stratification and procognitive treatments in schizophrenia.
\end{abstract}

Supplementary information The online version of this article (https:// doi.org/10.1038/s41380-019-0511-4) contains supplementary material, which is available to authorized users.

G. M. Leggio

gianmarco.leggio@unict.it

$\triangle$ F. Papaleo

francesco.papaleo@iit.it

1 Department of Biomedical and Biotechnological Sciences, University of Catania, Catania, Italy

2 Department of Neuroscience and Brain Technologies, Genetics of Cognition laboratory, Istituto Italiano di Tecnologia, via Morego, 30, 16163 Genova, Italy

3 Department of Biomedical Sciences, University of Cagliari, Cagliari, Italy

4 Department of Clinical and Experimental Medicine, University of Messina, Messina, Italy

\section{Introduction}

Dopaminergic receptors have important implications in several psychiatric and neurodevelopmental disorders [1]. Particularly for schizophrenia, converging physiological, anatomical, genetic, and pharmacological evidence strongly imply the importance of D2-like receptors [2-5]. In contrast to D1-like receptors (D1 and D5), members of the D2 receptor family (D2, D3, and D4) are quickly internalized after agonist stimulation and eventually degraded through the intracellular lysosomal pathway [6, 7]. Intracellular trafficking processes might be altered in schizophrenia [8-10] and are implicated in antipsychotic drug modes of action [11-15].

The dysbindin-1 (Dys) protein, encoded by the dystrobrevin-binding protein 1 gene (DTNBP1), is part of the biogenesis of lysosome-related organelles complex 1 and is implicated in intracellular trafficking processes $[16,17]$. In particular, genetic disruption of Dys alters the intracellular trafficking of D2-like but not D1 receptors, resulting in increased expression of D2 receptors on the neuronal surface $[16,18]$. Consistent with this observation, 
in both mice and humans, genetic variations in Dys affect cognition- and schizophrenia-relevant behavioral phenotypes through dopamine/D2-like mechanisms [19-22]. Furthermore, in both mice and humans, genetic variations in Dys alter cognitive responses to antipsychotic drugs through D2-mediated mechanisms [18]. However, the mechanism by which Dys-dependent modulation of D2-like receptor intracellular trafficking might selectively interact with D3 signaling is unknown.

Dopamine D2 and D3 receptors show high structural homology [23], and currently available pharmacological tools, as well as antipsychotic drugs have high affinity for both of these receptors [5, 24-26]. Thus, the unique contribution of each of these receptors to physiological and behavioral functions cannot be fully distinguished. This limitation is important to address, as recent electrophysiological and morphological analyses have identified distinct neuronal populations expressing either D2 or D3 receptors [27]. Furthermore, D2 and D3 receptors are suggested to differentially control mood and cognitive processes $[25,26]$ and might be implicated differently in psychiatric disorders and their pharmacological treatments [28, 29].

Here, we adopted a genetic approach to assess the selective contribution of D3 hypofunction in the context of Dysdependent alterations of D2-like intracellular trafficking. First, we discovered an epistatic functional interaction between D3 and Dys in patients with schizophrenia enrolled in the NIH Clinical Antipsychotic Trials of Intervention Effectiveness (CATIE) study. Subsequently, by establishing a mouse line with concomitant selective hypofunction of both the D3 and Dys genes (i.e., double heterozygous $\mathrm{D}^{+/-} \times \mathrm{Dys}^{+/-}$mice), we confirmed the functional interaction between D3 and Dys in schizophrenia-relevant phenotypes, as well as in neuronal excitability, extracellular dopamine levels, and responses to antipsychotic drugs. Our data support the hypothesis that D3 might be a pharmacological target for procognitive drug treatments, as well as a genetic tool for patient stratification toward more personalized treatments in schizophrenia.

\section{Materials and methods}

\section{Human subjects}

Patients were enrolled in the CATIE study through the NIMH Center for Collaborative Research and Genomics Resource [30, 31]. Analysis was carried out on samples from 662 patients with schizophrenia clinically assessed at baseline and with an 18-month follow-up for which cognitive and genetic data were available. Demographic and clinical details included age, sex, age of illness onset, illness duration, and medical (including alcohol and drug use), admission and medication histories. From the CATIE study, we selected the cognitive performance on the Wisconsin Card Sorting Test (WCST), a measurement widely used to assess executive function deficits associated with prefrontal cortex (PFC) function in patients with schizophrenia [32-34], and a composite measure of working memory (WM) based on the letter-number span test and a computerized test of visuospatial WM [31]. For details, see the Supplementary Information.

\section{Mice}

We established a novel mouse line first by breeding $\mathrm{D} 3^{-/-}$ [35] mice with Dys ${ }^{-/-}$[22] mice to obtain double D3 and Dys heterozygous $\left(\mathrm{D}^{+/-} \times \mathrm{Dys}^{+/-}\right)$mice. Both lines were on a C57BL/6J genetic background, which is commonly used to facilitate interlaboratory comparisons. Consistent with the idea that heterozygous mice might mimic human functional genetic variations better than full knockout mice $[18,36,37]$ and to avoid uncontrollable gene-environment interactions stemming from possible alterations in maternal behavior, we followed a breeding scheme consisting of mating one male $\mathrm{D}^{+/-} \times \mathrm{Dys}^{+/-}$mouse with two C57BL6/ $\mathrm{J}$ female mice. This approach allowed us to evaluate, in the generated littermates, the lifelong effects of genetic variations resulting in normal levels of both $\mathrm{D} 3$ and Dys $\left(\mathrm{D} 3^{+/+}\right.$ $\left.\times \mathrm{Dys}^{+/+}\right)$, selective D3 hypofunction $\left(\mathrm{D}^{+/-} \times \mathrm{Dys}^{+/+}\right.$ single heterozygous mice), Dys hypofunction $\left(\mathrm{D}^{+/+} \times\right.$ Dys $^{+/-}$single heterozygous mice), and decreased levels of both D3 and Dys in the same individual $\left(\mathrm{D}^{+/-} \times \mathrm{Dys}^{+/-}\right.$ mice). Only 3- to 6-month-old male littermates were tested to directly compare the results with our relevant previous study [18]. For detailes, see the Supplementary Information.

\section{Drugs and treatments}

Risperidone (Sigma, Dorset, UK), clozapine and blonanserin (Sigma-Aldrich, St. Louis, MO, United States) were dissolved in $20 \mu \mathrm{l}$ of acetic acid and further brought up to volume with physiological saline $(0.9 \% \mathrm{NaCl})$; the $\mathrm{pH}$ was adjusted to 6 with $0.1 \mathrm{M} \mathrm{NaOH}$. All drug solutions were prepared daily and administered intraperitoneally (i.p.) in an injection volume of $10 \mathrm{ml} / \mathrm{kg}$. For details, see the Supplementary Information.

\section{Behavioral tasks}

\section{Temporal order recognition (TOR) test}

This test was carried out as previously described $[8,38]$.

\section{Discrete paired-trial variable-delay T-maze task}

In this test $[22,39]$, mice were exposed to a sequence of randomly chosen forced runs, each followed by a choice run 
such that the mice were required to integrate information from the forced run with the learned rule (nonmatch to sample).

Acoustic startle response and prepulse inhibition (PPI) test

Before $2 \mathrm{~h}$ of the test, animals were acclimatized to the testing room. The acoustic startle response and PPI were measured using an SR-Lab System apparatus (San Diego Instruments, San Diego, CA, USA). The procedure was performed as previously described $[8,37]$.

\section{Open field test}

Animals were tested in an evenly illuminated $(9 \pm 1$ lux $)$ square open field, $40 \times 40 \times 40 \mathrm{~cm}$, divided into 16 quadrants by lines on the floor (Ugo Basile, Gemonio, Italy) over a 30-min period. Locomotor activity and rearing behavior were assessed during the first exposure to the empty open field arena.

\section{Habituation/dishabituation social interaction test}

Animals were tested as previously described [40] in slightly illuminated $(5 \pm 1$ lux $) 2150 \mathrm{E}$ Tecniplast cages $(35.5 \times$ $23.5 \times 19 \mathrm{~cm})$, and the test was video recorded using a video camera (Sony Videocam PJ330E).

For detailed information on the behavioral testing, see the Supplementary Information.

\section{RNA isolation and real-time PCR}

Total RNA was extracted from isolated brain areas [medial prefrontal cortex (mPFC) and striatum]. For details, see the Supplementary Information.

\section{Slices surface biotinylation}

Mice were anesthetized with isoflurane and were then decapitated. The brain was sectioned in cold carboxygenated Hanks' balanced salt solution (HBSS, Invitrogen Life Technologies) enriched with $4 \mathrm{mM} \mathrm{MgCl}_{2}, 0.7 \mathrm{mM}$ $\mathrm{CaCl}_{2}$, and $10 \mathrm{mM}$ D-glucose and equilibrated with $95 \% \mathrm{O}_{2}$ and $5 \% \mathrm{CO}_{2} ; \mathrm{pH}$ 7.4.) on a vibratome at a thickness of 300 $\mu \mathrm{m}$. The mPFC was dissected from coronal slices. For details, see the Supplementary Information.

\section{Electrophysiology}

\section{Slice preparation}

mPFC slices were prepared from mice of postnatal day (PND) 13 to PND 22.

\section{Whole-cell patch-clamp recordings}

Slices were transferred to a recording chamber, maintained at $30-32{ }^{\circ} \mathrm{C}$, and perfused with oxygenated regular artificial cerebrospinal fluid (ACSF) at $1 \mathrm{ml} / \mathrm{min}$. Neurons in the mPFC were visualized using two water immersion objectives (HCX/APO L 10X/0.30 and 40X/0.80) with infrared differential interference contrast (DMLFS microscope, Leica, Wetzlar, Germany) connected with an infraredsensitive camera. For details, see the Supplementary Information.

\section{In vivo microdialysis}

A concentric dialysis probe with a dialyzing portion of 2.0 $\mathrm{mm}$ was prepared as previously described [8, 41]. Mice were anesthetized with isoflurane and were then placed in a stereotaxic frame (Kopf Instruments, Tujunga, CA) for probe implantation. The probe was implanted into the mPFC according to the Paxinos and Franklin mouse brain atlas (AP: +1.9 ; ML: \pm 0.1 ; DV: -3.0 from the bregma). For details, see the Supplementary Information.

\section{Statistical analysis}

Data were analyzed using RStudio (v1.1.447, Boston, MA) or GraphPad Prism 7 (GraphPad Software, La Jolla, CA, USA). For details, see the Supplementary Information.

\section{Results}

\section{Epistatic interaction between D3 and Dys functional genetic variants affects cognitive functions in patients with schizophrenia}

We first investigated whether an epistatic interaction would be detectable in humans in clinical behavioral readouts. We analyzed data from 662 patients with schizophrenia extracted from the CATIE database, a data repository for a clinical trial that monitored these patients following assignment to an antipsychotic drug treatment [30]. Specifically, we investigated the interaction between the D3 receptor Ser/Gly rs6280 and the Dys rs1047631 functional genetic variants at the first (Month 0), after 6 months, and at last assessment (Month 18) of this clinical trial. Considering the drop out of patients between the different time points of assessments and some missing genetic data [18, 31, 42], we performed longitudinal analyses including those patients for which all cognitive and genetic data were available in all three assessment time points considered. Several consistent lines of evidence reported that the D3 haplotype rs6280 with the Ser allele is associated with a lower affinity for 
dopamine than the Gly allele [43] and that Dys rs1047631 TT carriers have decreased Dys expression [18] (Supplementary Fig. 1).

We examined the effect of the interaction between these genotypes on cognitive functions known to be altered in schizophrenia (i.e., executive functions and WM) and for which we could have equivalent tasks in mouse models [8, 18, 20, 44, 45]. Moreover, we assessed possible genotype-dependent effects on clinical symptom rating scales (i.e., the positive and negative syndrome scale (PANSS) score), both at baseline and at the end of the study.

A genotype-by-time of assessment effect was evident for the WCST score (Fig. 1a, and Supplementary Tables 1). Specifically, patients carrying genetic variants increasing Dys expression (C-carriers) and increasing D3 affinity for dopamine (Gly/Gly) had lower WCST scores than patients without these variants after 18th months follow-up and did show a cognitive deterioration with time (Fig. 1a, and Supplementary Tables 1). In contrast, there was a significant improvement in WCST score in TT-Ser/Gly, C-carriers Ser/ Ser, and TT-Ser/Ser patients (Fig. 1a, and Supplementary Tables 1). For the WM scores we observed a main effect of genotype and time, but no genotype-by-time interaction (Fig. 1b, and Supplementary Tables 1). Specifically, patients carrying genetic variants increasing Dys expression (C-carriers) and increasing D3 affinity for dopamine (Gly/ Gly) had lower WM scores than all other patients without these variants (Fig. 1b, and Supplementary Tables 1).

No genotype-by-time interaction was evident in the positive and total PANSS scores (Fig. 1c, e, and Supplementary Tables 1). For the PANSS negative scores, a significant genotype-by-time interaction showed an improvement with time in all genotypes, but no differences between genotypes within each single time of assessment (Fig. 1d, and Supplementary Tables 1). No significant differences in age, sex, or years of education were found between genotypes (Supplementary Tables 2). These results suggest an interaction between functional variants altering D3 and Dys expression that affects core cognitive deficits in schizophrenia.

\section{Epistatic interaction between D3 and Dys functional genetic variants affects cognitive functions in genetically modified mice with or without treatment with antipsychotics}

To selectively address the D3-Dys genetic interaction, we established a new mouse line with concomitant hypofunction of both the D3 and Dys genes (i.e., double heterozygous $\mathrm{D}^{+/-} \times \mathrm{Dys}^{+/-}$mice). This approach circumvented possible confounding factors linked with human studies, such as genetic heterogeneity, environmental effects, and pathological state. Specifically, reduced levels of both D3 and Dys in $\mathrm{D}^{+/-} \times \mathrm{Dys}^{+/-}$mice should approximate the human genetic condition of carriers of both the D3 Ser/Ser and Dys TT functional polymorphisms.

The cognitive deficits we found in the WCST and WM tasks in human patients (Fig. 1) are usually linked to dysfunctional dopaminergic signaling within the PFC [19, 31, 46-49]. Moreover, all patients with schizophrenia were under treatments with antipsychotic drugs. Thus, we first tested wild-type $\left(\mathrm{D}^{+/+} \times \mathrm{Dys}^{+/+}\right)$, single $\left(\mathrm{D}^{+/-} \times\right.$ $\mathrm{Dys}^{+/+}$and $\mathrm{D}^{+/+} \times \mathrm{Dys}^{+/-}$), and double mutant $\left(\mathrm{D} 3^{+/-} \times\right.$ $\mathrm{Dys}^{+/-}$) littermates in a TOR test that is sensitive to dopaminergic alterations within the mPFC [8], following no manipulations, or chronic treatments with vehicle or different antipsychotic drugs (Fig. 2a). In particular, we treated mice with risperidone (as one of the most commonly used antipsychotic [18]), clozapine (as the antipsychotic with a more different pharmacological profile and possibly higher therapeutic efficacy [5]), and blonanserin (for its antagonistic activity on D3 [50]).

Chronic treatment with all drugs rescued the TOR memory impairment seen in drug-naive $\mathrm{D}^{+/+} \times \mathrm{Dys}^{+/-}$mice (Fig. 2b, c). However, only risperidone and blonanserin improved the TOR performance of all mutant mice compared to vehicle- and drug-treated $\mathrm{D}^{+/+} \times \mathrm{Dys}^{+/+}$mice (Fig. 2b, c). Whereas no difference in the total amount of object exploration during the test phase was found between genotypes (Fig. 2d, e), $\mathrm{D}^{+/+} \times \mathrm{Dys}^{+/-}$naive mice showed a decrease of the total exploration of the objects only during the sample phase 1 (Supplementary Fig. 2a-d). Considering that risperidone was the only drug in common between the human (Fig. 1) and mouse data (Fig. 2), the cognitive performance of risperidone-treated mice was remarkably similar to that shown by patients with schizophrenia when stratified by D3 and Dys functional genetic variants (Fig. 1b, d vs Fig. 2c).

\section{D3 hypofunction improves PFC-dependent working memory}

We next aimed to further explore the consequences of the revealed D3-by-Dys genetic interaction in a more selective and demanding WM-discrete paired-trial variable-delay Tmaze task [22, 39], which also relies on mPFC functioning $[4,39]$ and is sensitive to dopaminergic modulation [22, 39].

All genotypes displayed delay-dependent performance, with a progressive increase in the number of errors with longer delays (Fig. 3a). As previously shown [20, 22], Dys single heterozygous $\left(\mathrm{D}^{+/+} \times \mathrm{Dys}^{+-}\right.$) mice performed worse than wild-type $\left(\mathrm{D}^{+/+} \times \mathrm{Dys}^{+/+}\right.$) mice at both the 4 and $30 \mathrm{~s}$ intra-trial intervals (Fig. 3a). Conversely, hypofunction of the D3 receptor gene rescued the Dys-dependent deficits and improved the WM performance of $\mathrm{D}^{+/-} \times \mathrm{Dys}^{+/-}$double heterozygous mice over that of wild-type mice (Fig. 3a). Mice of all genotypes required the same amount of time to learn the 


\section{D3 x Dys (rs6280 x rs1047631)}
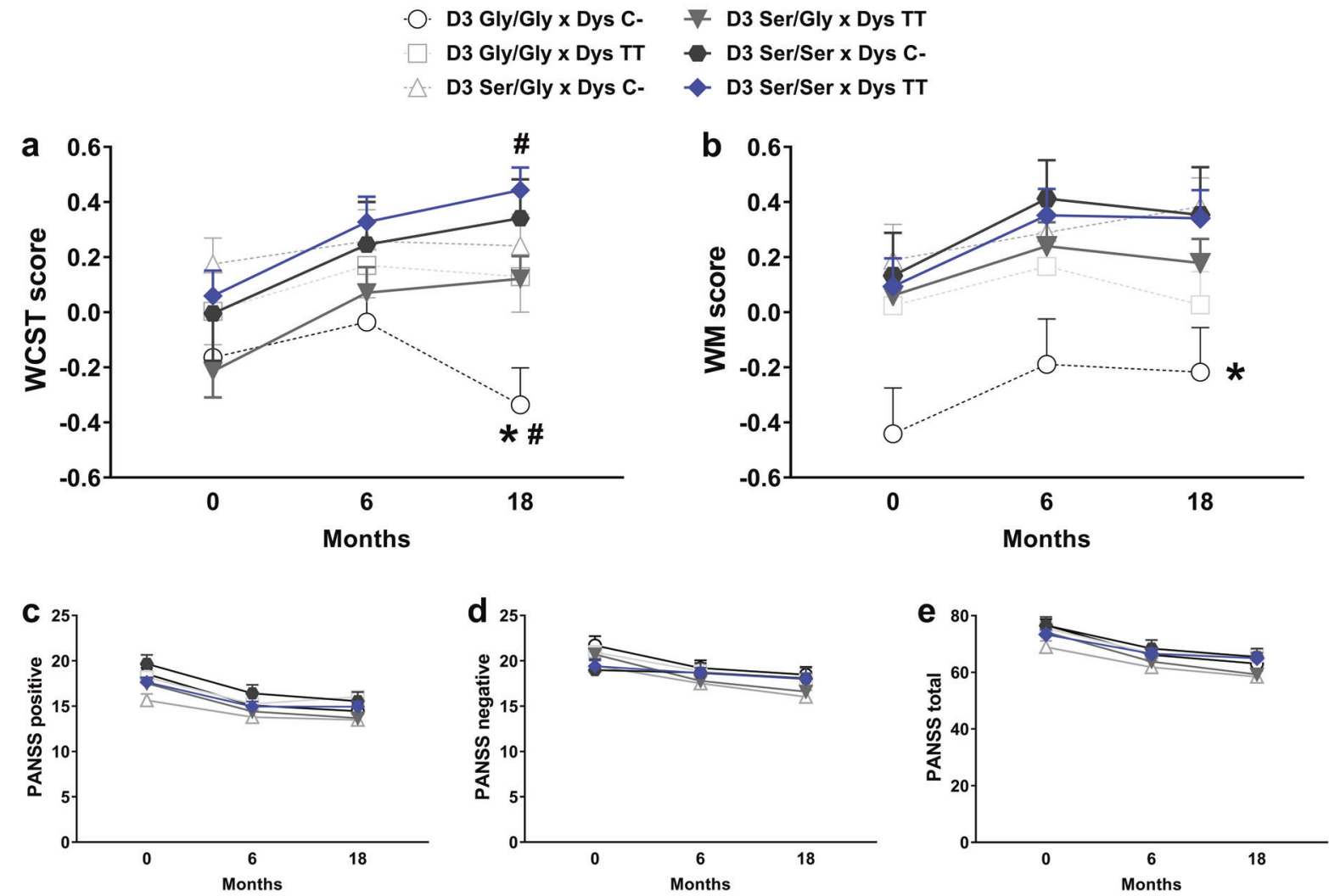

Fig. 1 Genetic variants that concomitantly and relatively increase both D3 affinity and Dys expression are associated with neurocognitive disadvantages in patients with schizophrenia. a Wisconsin Card Sorting Test (WCST) performance across genotypes at assessment month 0, 6, and 18. As extracted from the CATIE study [31], the WCST score was calculated by averaging $z$-scores for perseverative errors and categories achieved. Two-way ANOVA for test performance revealed a significant effect of genotype $\left[F_{(5,387)}=2.62, p=\right.$ $0.02]$, months of assessment $\left[F_{(2,774)}=12.85, p<0.0001\right]$, and a genotype-by-time interaction $\left[F_{(10,774)}=2.06, p=0.02\right]$. Post hoc: $* P$ $<0.05$ D3 Gly/Gly, Dys C-carrier subjects vs all other groups. ${ }^{\#} P<$ 0.05 vs 0 or 6 months performance within the same genotype group. Dotted line indicates genotypes not improving with time. b Working Memory (WM) composite score across genotypes at month 0,6 , and

basic version of the task (Fig. 3b). Moreover, mice of all genotypes learned equally to run quickly through the maze to retrieve the reward (Fig. 3c). Thus, concomitant D3/Dys hypofunction not only rescued the WM deficits related to Dys hypofunction but also improved working memory abilities on this mPFC-dependent task.

\section{Marginal effects of D3-Dys genetic interactions in social behavior, locomotor activity, startle and PPI responses}

Because D3-by-Dys effects in humans were most evident in cognitive abilities rather than other behavioral alterations
18 of assessment. As extracted from the CATIE study [31], the WM score refers to the CATIE variable "Memory_S" and it was calculated by standardizing to baseline mean of performance in the letter-number span test and a computerized test of visuospatial working memory. Two-way ANOVA for test performance showed a significant effect of genotype $\left[F_{(5,394)}=2.41, p=0.036\right]$, months of assessment $\left[F_{(2,788)}=\right.$ $14.91, p<0.0001]$, but no genotype-by-time interaction $\left[F_{(10,788)}=\right.$ $0.82, p=0.61]$. Post hoc: $* P<0.05$ D3 Gly/Gly, Dys C-carrier subjects vs all other genotypes groups. Dotted line indicate genotypes not improving with time. Two-way ANOVA for positive scale (c: [genotype-by-time $\left.F_{(10,856)}=1.20, p=0.28\right]$ ), negative scale (d: [genotype-by-time $F_{(10,856)}=2.07, p=0.025$ ], total score (e: [genotype-bytime $\left.\left.F_{(10,856)}=1.38, p=0.19\right]\right)$. The values are the means \pm s.e.m.

(i.e., PANSS scores, Fig. 1), we next tested D3-Dys mutant mice in other behavioral processes that might be relevant for schizophrenia-like behavioral alterations.

Concomitant D3/Dys hypofunction did not rescue Dysdependent social behavioral deficits. Indeed, both $\mathrm{D} 3^{+/+} \times$ Dys $^{+/-}$and $\mathrm{D}^{+/-} \times \mathrm{Dys}^{+/-}$mice exhibited social interaction deficits in a habituation/dishabituation social interaction test (Fig. 3d), while single partial deletion of D3 did not affect social behaviors (Fig. 3d). Thus, D3 hypofunction has negligible effect on sociability/social novelty measures, which might be related to negative symptoms of schizophrenia.

Consistent with previous reports [22, 35], both Dys $\left(\mathrm{D}^{+/+} \times \mathrm{Dys}^{+/-}\right)$and D3 $\left(\mathrm{D}^{+/-} \times \mathrm{Dys}^{+/+}\right)$single 


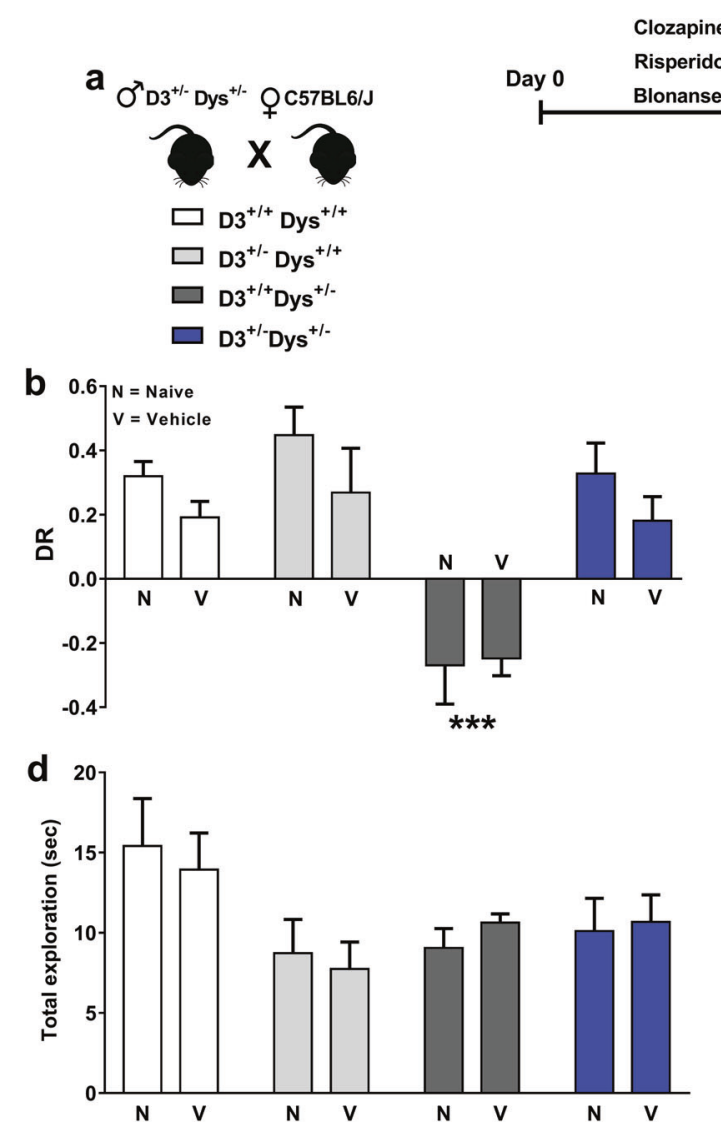

Fig. 2 D3 hypofunction improves the efficacy of antipsychotics on improving cognitive functions in mice with genetic reduction of Dys expression. a D3 $3^{+/-} \times \mathrm{Dys}^{+/-}$double mutant (purple bar), $\mathrm{D}^{+/+} \times$ $\mathrm{Dys}^{+/-}$(dark gray bar), D3 ${ }^{+/-} \times \mathrm{Dys}^{+/+}$(gray bar) and wild-type $\mathrm{D}^{+/+} \times \mathrm{Dys}^{+/+}$(white bar) littermate mice were generated by mating $\mathrm{D}^{+/-} \times \mathrm{Dys}^{+/-}$males with naive C57BL6/J female mice. The different experimental groups of mice were treated with drug or vehicle once daily for 14 consecutive days before the TOR test. b Discrimination ratio (DR) displayed by naive $\left[\mathrm{D}^{+/+} \times \mathrm{Dys}^{+/+}(n=8)\right.$, $\mathrm{D}^{+/-} \times \mathrm{Dys}^{+/+}(n=5), \quad \mathrm{D}^{+/+} \times \mathrm{Dys}^{+/-} \quad(n=6), \quad \mathrm{D}^{+/-} \times \mathrm{Dys}^{+/-}$ $(n=6)]$ and vehicle-treated mice $\left[\mathrm{D}^{+/+} \times \mathrm{Dys}^{+/+}(n=9), \mathrm{D}^{+/-} \times\right.$ $\left.\mathrm{Dys}^{+/+}(n=7), \quad \mathrm{D}^{+/+} \times \mathrm{Dys}^{+/-}(n=7), \quad \mathrm{D}^{+/-} \times \mathrm{Dys}^{+l-}(n=7)\right]$ during the 5 -min test phase of the TOR test. Two-way ANOVAs revealed a genotype effect $\left[F_{(3,47)}=20.26 ; P<0.0001\right]$. Post hoc: $* * * P<0.001$ vs naive or vehicle-treated $\mathrm{D}^{+/+} \times \mathrm{Dys}^{+/+}$mice. $\mathbf{c ~ D R}$ displayed by drug-treated mice [clozapine: $\mathrm{D}^{+/+} \times \mathrm{Dys}^{+/+}(n=8)$,

heterozygous mice were more active than their wild-type littermates $\left(\mathrm{D}^{+/+} \times \mathrm{Dys}^{+/+}\right)$when tested in an open field arena. In contrast, $\mathrm{D}^{+/-} \times \mathrm{Dys}^{+/-}$double heterozygous mice showed wild-type-like behavior (Fig. 3e). Analysis of rearing behavior revealed no differences among the genotypes (Fig. 3f). Thus, the concomitant reduction in D3 and Dys gene expression abolished the hyperactive phenotype produced by either genetic variant.

Startle and PPI responses to an acoustic startle stimulus can be measured in mice and humans [51-53], and decreased PPI is found in patients with schizophrenia [54], as well as in mouse models relevant to schizophrenia $[8,55,56]$. In Dys single heterozygous $\left(\mathrm{D}^{+/+} \times \mathrm{Dys}^{+/-}\right)$mice, startle reactivity was increased (Fig. 3g), consistent with previous findings [22]. Conversely, D3 single heterozygous mice $\left(\mathrm{D}^{+/-} \times\right.$ Dys $^{+/+}$), in agreement with findings from other studies [57], were less reactive to the startle stimulus than wild-type mice (Fig. 3g). In contrast, wild-type-like reactivity to the startle stimulus was restored in double heterozygous $\left(\mathrm{D}^{+/-} \times\right.$ Dys $^{+-}$) mice (Fig. 3g). The levels of basal activity in the apparatus in the absence of a stimulus did not differ among genotypes (Fig. 3g). Similar to the locomotor activity results, 

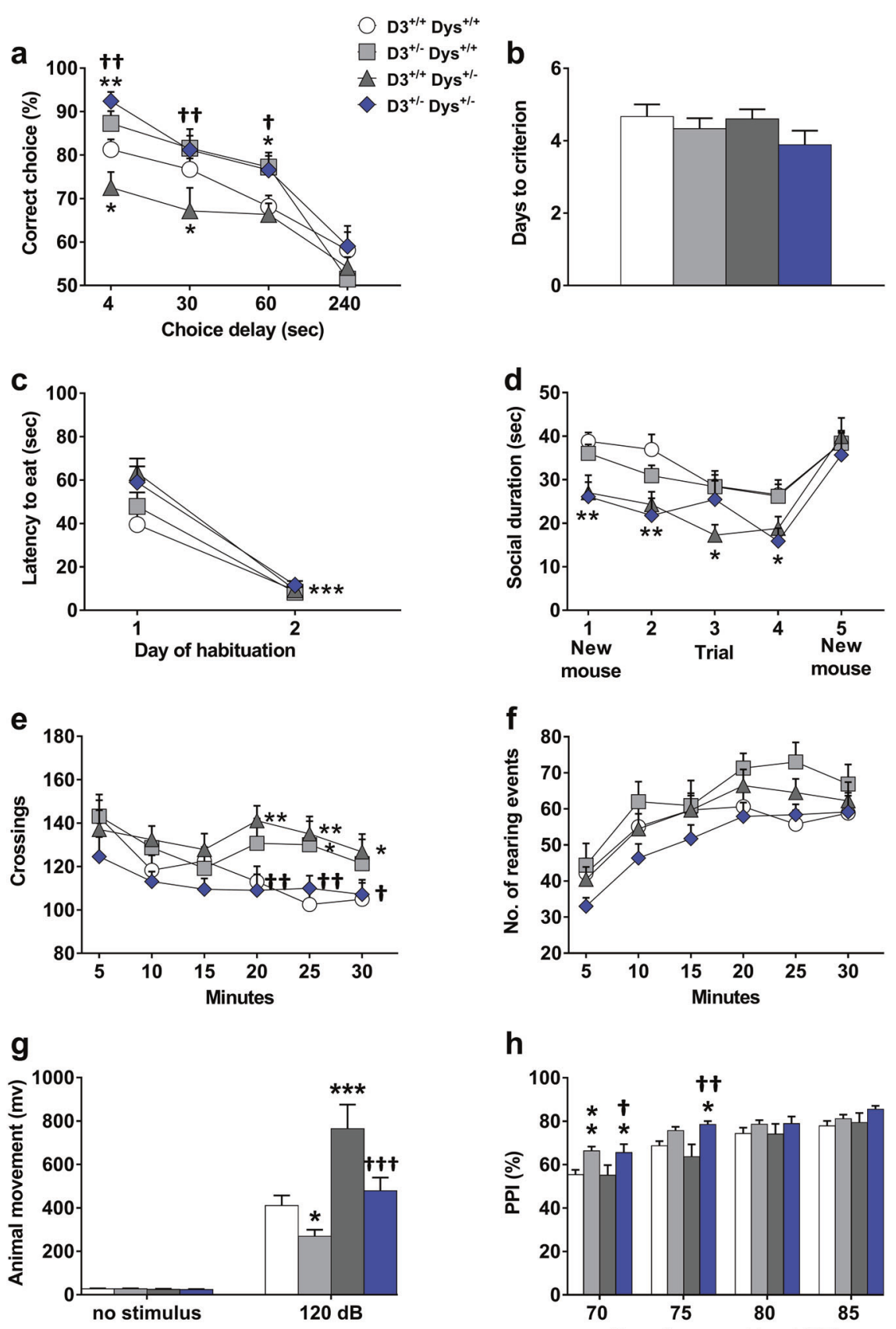

h

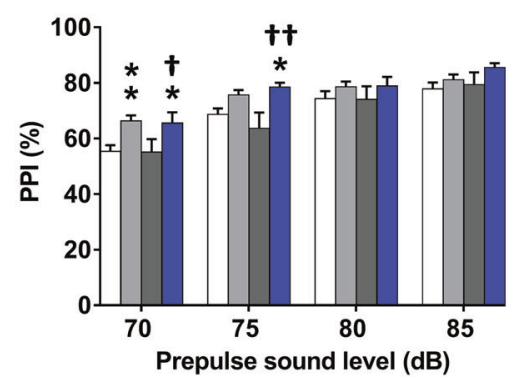

these results show that concomitant partial disruption of the D3 and Dys genes rescues the alterations in startle responses driven by each single mutation.

Consistent with evidence that startle and PPI responses are distinct behavioral responses [58], we found a distinct impact of D3/Dys genotypes in PPI measures compared to that in startle reactivity. In fact, in contrast to Dys single heterozygous $\left(\mathrm{D}^{+/+} \times \mathrm{Dys}^{+/-}\right)$mice but similar to D3 single heterozygous $\left(\mathrm{D}^{+/-} \times \mathrm{Dys}^{+/+}\right)$mice, $\mathrm{D}^{+/-} \times$ Dys $^{+/-}$double heterozygous mice exhibited a PPI response higher than that in both wild-type and $\mathrm{D}^{+/+} \times \mathrm{Dys}^{+/-}$mice

(Fig. 3h). Overall, these results show that concomitant D3 and Dys hypofunction returned the locomotor and startle alterations caused by single disruption of the D3 or Dys gene to wild-type levels.

\section{Epistatic interaction between D3 and Dys functional genetic variants produces different molecular outcomes in the cortex and the striatum}

Prompted by the behavioral effects driven by D3-by-Dys genetic interaction, we sought to identify if this would be 
Fig. 3 Partial deletion of the D3 gene rescues the working memory (WM) deficits of Dys mutant mice, while having marginal effects in social behavior, locomotor activity, startle, and PPI responses. a Percentage of correct choices displayed by $\mathrm{D}^{+/+} \times \mathrm{Dys}^{+/+}(n=12)$, $\mathrm{D}^{+/-} \times \mathrm{Dys}^{+/+}(n=9), \mathrm{D}^{+/+} \times \mathrm{Dys}^{+/-}(n=10)$, and D3 ${ }^{+/-} \times \mathrm{Dys}^{+/-}$ $(n=9)$ mice during the discrete paired-trial variable-delay $T$-maze test with different randomly presented intratrial delays $(4,30,60$, and 240 s) and an intertrial delay of $20 \mathrm{~s}$. The $50 \%$ value corresponds to chance levels of correct choices. Repeated measures ANOVAs revealed a genotype effect $\left[F_{(3,36)}=8.351, P=0.0002\right]$ and a delay effect $\left[F_{(3,108)}=50.35, P<0.0001\right]$. b Days needed to meet the criterion and c latency to retrieve the hidden food pellet during the discrete pairedtrial $T$-maze task. No differences were found among genotypes in task acquisition [one-way ANOVA, genotype effect: $F_{(3,36)}=1.152, P=$ 0.3413 ] or food retrieval [two-way ANOVA, genotype effect: $F_{(3,36)}$ $=2.542, P=0.0716$; and day effect: $\left.F_{(1,36)}=143.3, P<0.0001\right]$. d Time spent by $\mathrm{D}^{+/+} \times \mathrm{Dys}^{+/+}(n=15), \mathrm{D}^{+/-} \times \mathrm{Dys}^{+/+}(n=16)$, $\mathrm{D}^{+/+} \times \mathrm{Dys}^{+/-}(n=11)$, and $\mathrm{D}^{+/-} \times \mathrm{Dys}^{+/-}(n=9)$ mice in investigating the same unfamiliar male mouse during each of four successive 1-min trials. A fifth 'dishabituation' trial shows the social investigation activity of the subject mice to the presentation of a new unfamiliar male mouse. Repeated measures ANOVAs revealed a genotype effect $\left[F_{(3,47)}=3.793 ; P=0.0162\right]$ and a trial effect $\left[F_{(4,188)}\right.$ $=25.71 ; P<0.0001]$ e, $\mathbf{f ~ D} 3^{+/+} \times \mathrm{Dys}^{+/+}(n=14), \mathrm{D}^{+/-} \times \mathrm{Dys}^{+/+}$ $(n=10), \mathrm{D}^{+/+} \times \mathrm{Dys}^{+l-}(n=15)$, and $\mathrm{D}^{+l-} \times \mathrm{Dys}^{+/-}(n=13)$ mice were tested in an open field arena for $30 \mathrm{~min}$. Repeated measures ANOVAs revealed a genotype effect $\left[F_{(3,48)}=3.374 ; P=0.0258\right]$ and a time effect $\left[F_{(5,240)}=6.026 ; P<0.001\right]$ on locomotor activity (crossings, e), but did not show a genotype effect $\left[F_{(3,48)}=1.742 ; P=\right.$ $0.171]$ on rearing behavior $(\mathbf{f})$. $\mathbf{g}$ Movement by $\mathrm{D}^{+/+} \times \mathrm{Dys}^{+/+}(n=$ $24), \mathrm{D}^{+/-} \times \mathrm{Dys}^{+/+}(n=23), \mathrm{D}^{+/+} \times \mathrm{Dys}^{+/-}(n=17)$ and D $3^{+/-} \times$ Dys $^{+-}(n=13)$ littermates during no-stimulus trials or following the presentation of a 120-dB stimulus (Startle). Two-way ANOVAs revealed a stimulus $\mathrm{x}$ genotype interaction $\left[F_{(3,146)}=11.02, P<\right.$ $0.001]$, a stimulus effect $\left[F_{(1,146)}=197.2, P<0.001\right]$ and a genotype effect $\left[F_{(3,146)}=10.73 ; P<0.001\right]$. h Percent PPI of the acoustic startle response exhibited by the same mice after the presentation of 70-, 75-, 80-, and 85-prepulse sound stimuli. Repeated measures ANOVAs revealed a stimulus $\mathrm{x}$ genotype interaction $\left[F_{(9,219)}=2.034\right.$, $P=0.0369]$, a stimulus effect $\left[F_{(3,219)}=93.52, P<0.001\right]$ and a genotype effect $\left[F_{(3,73)}=2.893 ; P=0.0410\right]$. Post hoc: $* * * P<$ $0.001, * * P<0.01, * P<0.05$ vs $\mathrm{D}^{+/+} \times \mathrm{Dys}^{+/+}$mice and ${ }^{\dagger \dagger} P<$ $0.001,{ }^{\dagger} P<0.01,{ }^{\dagger} P<0.05$ vs $\mathrm{D}^{+/+} \times \mathrm{Dys}^{+/-}$mice. The values are the means \pm s.e.m.

paralleled by relevant interactions at the molecular level. We focused on the mPFC and striatum as the main areas involved in the dopamine hypothesis of schizophrenia $[3,59]$.

We found increased levels of D3 mRNA expression in Dys $^{+/-}$mice in both the mPFC (Fig. 4a) and striatum (Fig. 4b). These increased D3 levels were reversed to wildtype levels in $\mathrm{D}^{+/-} \times \mathrm{Dys}^{+/-}$double mutant mice (Fig. 4a, b). In contrast, Dys mRNA expression was decreased in the mPFC of both $\mathrm{D}^{+/+} \mathrm{Dys}^{+/-}$and $\mathrm{D}^{+/-} \times \mathrm{Dys}^{+/-}$mice (Fig. 4c). However, Dys expression in the striatum was increased in $\mathrm{D}^{+/-}$mice, but this increase was reversed in $\mathrm{D}^{+/-} \times$Dys $^{+/-}$double mutant mice (Fig. 4d). Alterations in Dys expression can change D2 recycling [16, 22]. Thus, we analyzed the total and surface protein levels of D2-like receptors. The total levels of D2-like receptor expression in both the $\mathrm{mPFC}$ and striatum were unchanged by alterations in either the Dys or D3 genotype individually or interactively (Fig. 4e, f), consistent with previous findings $[8,16]$. Single mutant-induced D3 hypofunction did not alter D2-like receptor cell surface expression, while single mutant-induced Dys hypofunction increased D2-like receptor expression on the cell surface in both the mPFC and striatum (Fig. 4g, h), consistent with findings from previous studies [8]. However, in the mPFC of $\mathrm{D}^{+/-} \times$ Dys $^{+/-}$mice, an even larger increase in cell surface D2-like receptor expression was detected (Fig. 4g). In contrast, cell surface D2-like receptor expression in the striatum was returned to the wild-type level in $\mathrm{D}^{+/-} \times \mathrm{Dys}^{+/-}$double heterozygous mice (Fig. 4h). Overall, these results confirmed a genetic interaction between D3 and Dys functional variants in mice. Moreover, these data indicate that the D3/ Dys interaction might act differently in the PFC and the striatum.

\section{D3 hypofunctioning rescues Dys-dependent physiological alterations in the MPFC}

Both the human and mouse data suggested a D3-by-Dys genetic interaction in PFC-dependent cognitive functions. Thus, we investigated more in depth the physiological role of the D3/Dys interaction in the mPFC.

Whole-cell recordings were performed on layer $\mathrm{V}$ in mPFC slices because D 3 is mainly expressed in this cortical layer $[27,46]$. The firing frequencies increased in parallel with the injected current for all genotypes $\left(\mathrm{D}^{+/+} \times \mathrm{Dys}^{+/+}\right.$, $\mathrm{D}^{+/+} \times \mathrm{Dys}^{+/-}, \mathrm{D}^{+/-} \times \mathrm{Dys}^{+/+}$, and $\mathrm{D}^{+/-} \times \mathrm{Dys}^{+/-}$). However, increasing the current injection from 50 to 200 pA induced fewer spikes in the pyramidal neurons of $\mathrm{D}^{+/+} \times \mathrm{Dys}^{+/-}$mice than in those of wild-type mice (Fig. 5a, b). This difference was particularly marked at the $1 \mathrm{~s}$ and $150 \mathrm{pA}$ depolarization steps (Fig. 5b inset). This phenotype was partially ameliorated in double mutant $\left(\mathrm{D}^{+/-} \times \mathrm{Dys}^{+-}\right)$mice, as the spike frequency of neurons was not statistically different from that in wild-type mice (Fig. 5a, b). These data indicate that D3 hypofunction ameliorated the disrupted excitability of layer $\mathrm{V}$ pyramidal neurons triggered by Dys reduction.

To investigate whether these electrophysiological changes could be associated with altered dopaminergic transmission, we performed an in vivo microdialysis assessment in the mPFC of freely moving mice with D3 and/or Dys mutation (Fig. 5c). The basal extracellular dopamine levels in the mPFC were higher in single heterozygous Dys $\left(\mathrm{D}^{+/+} \times \mathrm{Dys}^{+/-}\right)$mice than in wild-type $\left(\mathrm{D}^{+/+} \times \mathrm{Dys}^{+/+}\right)$ mice. In contrast, $\mathrm{D}^{+/-} \times \mathrm{Dys}^{+/-}$double heterozygous mice exhibited restored, wild-type-like dopamine levels (Fig. 5c). Risperidone treatment restored the basal 

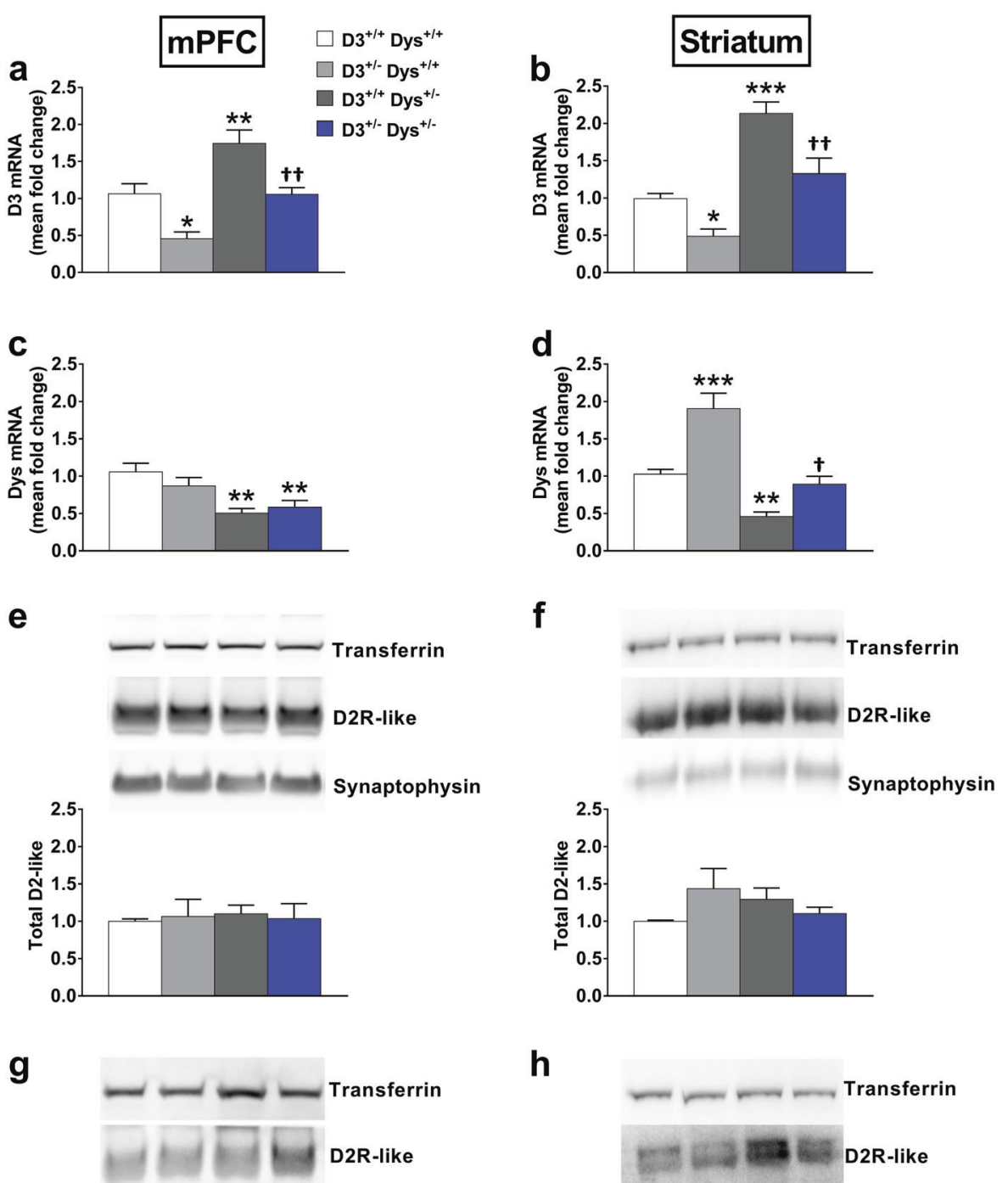

$\mathbf{h}$
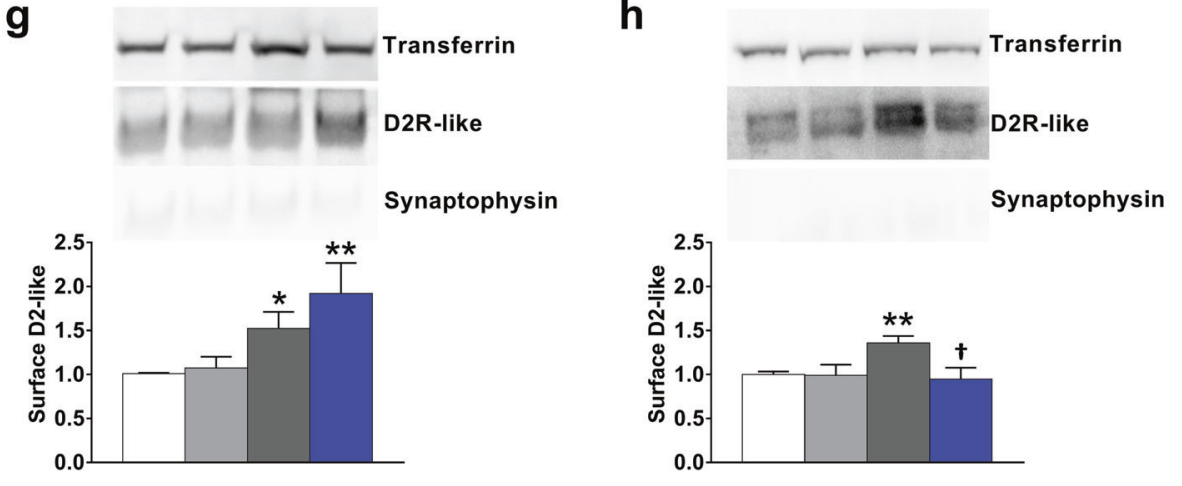

dopamine to wild-type levels in Dys ${ }^{+/-}$mice but did not affect $\mathrm{D}^{+/-} \times \mathrm{Dys}^{+/-}$or wild-type mice $\left(\mathrm{D}^{+/+} \times \mathrm{Dys}^{+/+}\right.$; Fig. 5d).

Notably, the infusion of the D2-preferring agonist quinpirole into the mPFC by reverse dialysis in freely moving mice, revealed that the functionality of D2-like receptors was disrupted in single D3 heterozygous Dys $\left(\mathrm{D}^{+/-} \times\right.$ $\mathrm{Dys}^{+/+}$) mice, but restored in double heterozygous $\left(\mathrm{D}^{+/-} \times\right.$Dys $^{+/-}$; Fig. 5e). Furthermore, following risperidone treatment, quinpirole had again no effects on dopamine levels in single D3 heterozygous $\left(\mathrm{D}^{+/-} \times \mathrm{Dys}^{+/+}\right.$; Fig. 5f), but increased dopamine levels in $\mathrm{D}^{+/-} \times \mathrm{Dys}^{+/-}$

double heterozygous mice (Fig. 5f, g). These results are similar to the quinpirole-induced increase in mPFC dopamine levels found in risperidone-treated Dys ${ }^{+/-}$mice with lentiviral-mediated D2 silencing [18], they might be related to the unselective nature of risperidone and/or quinpirole towards D2 and D3, and further support the D2/D3 imbalance in $\mathrm{D} 3^{+/-} \times \mathrm{Dys}^{+/-}$double heterozygous mice.

Taken together, these electrophysiological and neurochemical data show that D3 hypofunction can ameliorate Dys-dependent neuronal and dopaminergic basal abnormalities in the mPFC. Moreover, combined with the biochemical data obtained (Figs. 4 and 5), these data 
Fig. 4 D3/Dys epistatic interaction normalizes single-gene molecular changes in the striatum while generating a D2/D3 imbalance in the medial prefrontal cortex (mPFC). a, b Abundance of D3 in the mPFC $\left[\mathrm{D} 3^{+/+} \times \mathrm{Dys}^{+/+}(n=5), \mathrm{D}^{+/-} \times \mathrm{Dys}^{+/+}(n=6), \mathrm{D}^{+/+} \times \mathrm{Dys}^{+/-}(n\right.$ $\left.=6), \mathrm{D}^{+/-} \times \mathrm{Dys}^{+/-}(n=6)\right]$ and striatum $\left[\mathrm{D}^{+/+} \times \mathrm{Dys}^{+/+}(n=5)\right.$, $\mathrm{D}^{+l-} \times \operatorname{Dys}^{+/+}(n=5), \mathrm{D}^{+/+} \times \operatorname{Dys}^{+l-}(n=6), \mathrm{D}^{+l-} \times \operatorname{Dys}^{+/-}(n$ $=6)$ ] measured by quantitative RT-PCR. $\mathbf{c}, \mathbf{d}$ Abundance of Dys in the $\operatorname{mPFC}\left[\mathrm{D} 3^{+/+} \times \mathrm{Dys}^{+/+}(n=11), \mathrm{D}^{+/-} \times \mathrm{Dys}^{+/+}(n=10), \mathrm{D}^{+/+} \times\right.$ Dys $\left.^{+/-}(n=10), \mathrm{D}^{+/-} \times \mathrm{Dys}^{+/-}(n=9)\right]$ and striatum $\left[\mathrm{D} 3^{+/+} \times \mathrm{Dys}^{+/+}\right.$ $(n=9), \mathrm{D}^{+/-} \times \mathrm{Dys}^{+/+}(n=10), \mathrm{D}^{+/+} \times \mathrm{Dys}^{+/-}(n=11), \mathrm{D}^{+/-} \times$ Dys $\left.^{+/-}(n=10)\right]$ measured by quantitative RT-PCR. Mean fold changes are expressed relative to transcript levels in control mice $\left(\mathrm{D}^{+/+} \times \mathrm{Dys}^{+/+}\right)$. One-way ANOVAs revealed a genotype effect for D3 expression in the $\mathrm{mPFC}\left[F_{(3,20)}=16.8 ; P<0.001\right]$ and striatum $\left[F_{(3,18)}=20.76 ; P<0.001\right]$ and a genotype effect for Dys in the $\operatorname{mPFC}\left[F_{(3,36)}=6.95 ; P<0.001\right]$ and striatum $\left[F_{(3,36)}=25.02 ; P<\right.$ $0.001]$. e, f Western blot and densitometric analysis of total expression of D2-like receptors $(52 \mathrm{kDa})$ in the $\mathrm{mPFC}\left[\mathrm{D}^{+/+} \times \mathrm{Dys}^{+/+}(n=8)\right.$, $\mathrm{D}^{+/-} \times \mathrm{Dys}^{+/+}(n=6), \quad \mathrm{D} 3^{+/+} \times \mathrm{Dys}^{+/-}(n=5), \quad \mathrm{D}^{+/-} \times \mathrm{Dys}^{+/-}$ $(n=6)]$ and striatum $\left[\mathrm{D}^{+/+} \times \operatorname{Dys}^{+/+}(n=9), \mathrm{D}^{+/-} \times \mathrm{Dys}^{+/+}(n=6)\right.$, $\left.\mathrm{D}^{+/+} \times \operatorname{Dys}^{+/-}(n=7), \mathrm{D}^{+/-} \times \operatorname{Dys}^{+-}(n=7)\right] . \mathbf{g}, \mathbf{h}$ Western blot and densitometric analysis of surface expression of D2-like receptors $(52 \mathrm{kDa})$ in the $\mathrm{mPFC}\left[\mathrm{D}^{+/+} \times \mathrm{Dys}^{+/+}(n=9), \mathrm{D}^{+/-} \times \mathrm{Dys}^{+/+}(n=\right.$ $\left.6), \mathrm{D}^{+/+} \times \mathrm{Dys}^{+/-}(n=6), \mathrm{D}^{+l-} \times \mathrm{Dys}^{+/-}(n=6)\right]$ and striatum $\left[\mathrm{D}^{+/+} \times \mathrm{Dys}^{+/+}(n=9), \mathrm{D}^{+/-} \times \mathrm{Dys}^{+/+}(n=6), \mathrm{D}^{+/+} \times \mathrm{Dys}^{+/-}(n\right.$ $\left.=7), \mathrm{D}^{+/-} \times \operatorname{Dys}^{+l-}(n=7)\right]$. The results presented are normalized to transferrin receptor protein $(95 \mathrm{kDa})$ levels and to the $\mathrm{D}^{+/+} \times \mathrm{Dys}^{+/+}$ control group average. Synaptophysin $(39 \mathrm{kDa})$ was used as the cytosolic control. One-way ANOVAs revealed no genotype effect for the total level of $\mathrm{D} 2$ receptor expression in either the $\operatorname{mPFC}\left[F_{(3,21)}=\right.$ $0.0753, P=0.972]$ or striatum $\left[F_{(3,25)}=1.963, P=0.145\right]$. One-way ANOVAs revealed a genotype effect for surface D2 receptor expression in both the $\operatorname{mPFC}\left[F_{(3,23)}=5.382, P=0.0059\right]$ and striatum $\left[F_{(3,25)}=4.4296, P=0.0125\right]$. Post hoc: $* * * P<0.001, * * P<0.01$, ${ }^{*} P<0.05 \mathrm{vs} \mathrm{D}^{+/+} \times \mathrm{Dys}^{+/+}$mice. ${ }^{\dagger \dagger} P<0.01,{ }^{\dagger} P<0.05 \mathrm{vs} \mathrm{D}^{+/+}$Dys

${ }^{+/-}$mice. Each histogram shows the mean \pm s.e.m.

indicate that in the PFC, the D3-Dys interaction produced a D2/D3 imbalance favoring increased D2 neuronal surface levels, with normalized basal extracellular dopamine levels. Potentiation of D2 signaling in the PFC in the context of normalized dopamine levels improves higher-order cognitive functions [18]. Thus, these findings are consistent with the improved WM performance driven by D3 hypofunctioning in the context of reduced Dys expression.

\section{Discussion}

This study reveals an epistatic (gene-by-gene) interaction between D3 and Dys (DTNBP1) genes. In particular, Dysdependent alterations in the intracellular trafficking of D2-like receptors interact with $\mathrm{D} 3$ receptors, exerting prominent effects on higher-order cognitive functions in both humans and mice.

The approach employed, wherein functional genetic variants change the relative expression of different genes simultaneously, allows us to distinguish phenotypes regulated by epistasis (gene-by-gene interaction) from phenotypes for which D3 and Dys exert independent or no effects. Moreover, the similar findings in humans and mice strengthen the conclusion that a concomitant reduction in D3 and Dys functionality yields cognitive advantages in patients with schizophrenia. Indeed, the cognitive deficits measured by the WCST and WM tasks are described as core cognitive features of schizophrenia and are related to dopamine signaling within the PFC [20, 32, 44, 45, 47, 48]. Similarly, both the TOR and the WM task used here in mice relies on $\mathrm{mPFC}$ functioning and dopaminergic modulation $[4,8,22,45]$. We previously demonstrated that higher-order cognitive functions modulated by Dys depend on D2 receptor signaling within the PFC $[18,20,22]$. However, in addition to D2, D3 might be highly clinically relevant, because most currently prescribed antipsychotic drugs bind with similar affinity to D2 and D3 receptors $[5,24,49]$. Notably, the effects that we found were more prominent in cognitive functions relevant to schizophrenia while no D3by-Dys interaction was observed for general clinical assessments, such as positive and negative PANSS scores in humans and social behavior in mice. This finding could agree with those from studies suggesting that D3 blockade enhances cognitive functions $[26,60]$ without inducing the D2-related side effects of antipsychotic drugs [5, 25]. Furthermore, consistent with previous findings [29], D3 genetic hypofunction increased the scores for the PPI, a sensorimotor gating ability that is usually impaired in patients with schizophrenia [53]. Thus, from a clinical perspective, our current findings suggest that the beneficial cognitive effects of D3 blockade should be considered in combination with epistatic interactions with the Dys gene.

Our molecular data reinforce the meaning of the D3/Dys genetic interaction. Specifically, D3 expression altered by single genetic variants of either D3 or Dys was restored to the wild-type level in both the $\mathrm{mPFC}$ and striatum of D3 ${ }^{+/-} \times \mathrm{Dys}^{+/-}$double mutant mice. This pattern is consistent with that found in a recent in vitro study, showing that Dys might also influence the expression of D3 receptors [61]. In contrast, D3/Dys genetic interaction rescued Dys expression to the wild-type level in the striatum but not in the PFC. In support of this area-specific effect, we found that D2 receptor trafficking was rescued in $\mathrm{D}^{+/-} \times \mathrm{Dys}^{+/-}$double mutant mice to the wild-type-level in the striatum but not in the PFC. Indeed, Dys expression levels are strictly linked to D2-like receptor trafficking [16, 18, 22]. This D3/Dys epistatic normalization of striatal D2-like receptor signaling was further corroborated by the normalized locomotor activity and startle reactivity. Unlike in the striatum, in the PFC, D3-Dys interaction produced a D2/D3 imbalance favoring increased D2 neuronal surface levels, with normalized basal extracellular dopamine levels. Potentiation of D2 signaling in the PFC in the context of normalized dopamine levels improves higher-order cognitive functions [18]. Thus, these findings are consistent with the improved 

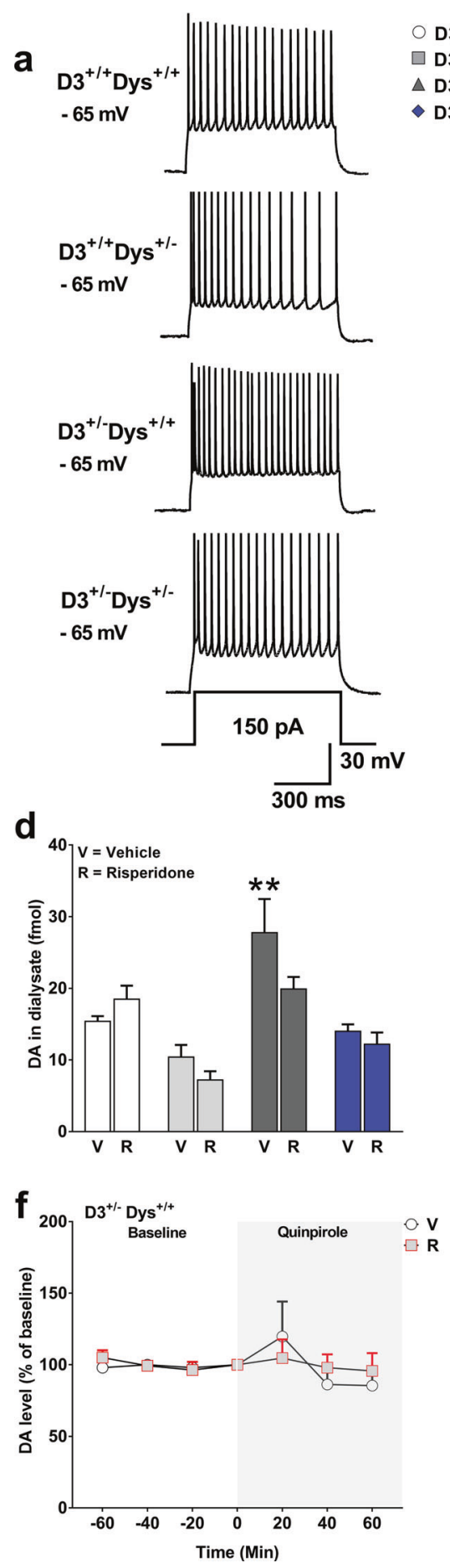

cognitive performance driven by $\mathrm{D} 3$ hypofunction in the context of reduced Dys expression.

The differential effect of D3/Dys interaction on the relative D2/D3 balance in the striatum vs that in the PFC suggests a distinctive region-specific effect requiring further investigation. However, in contrast to the striatum, which contains only two principal classes of medium spiny neurons coexpressing D2 and D3, the PFC features D3 receptor
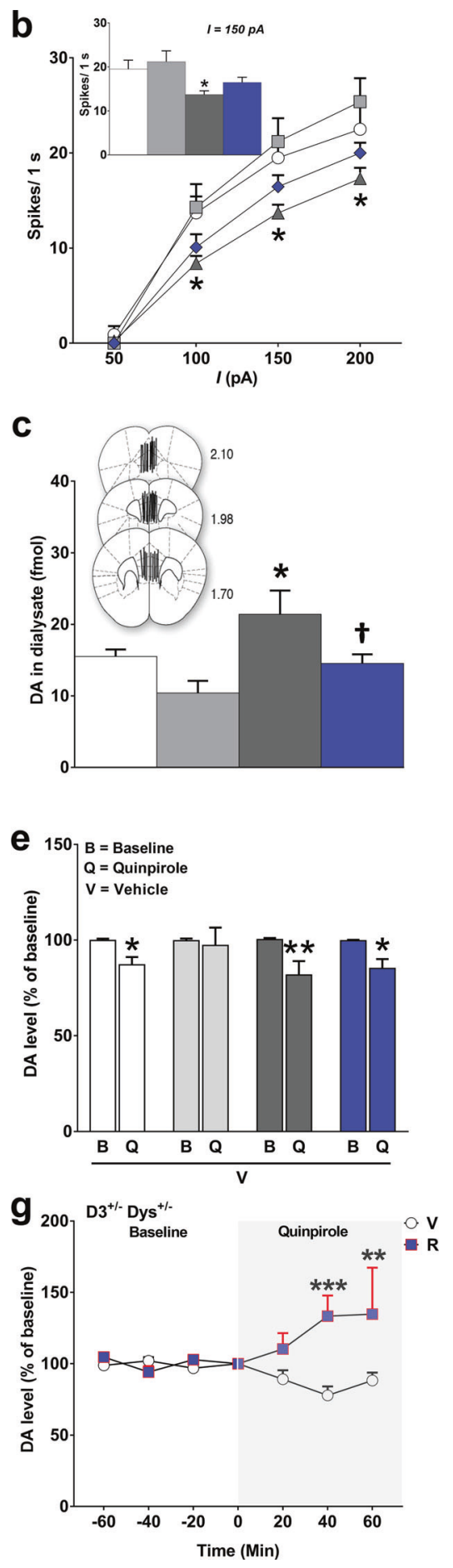

expression in a subclass of L5 pyramidal cells distinct from D1- and D2-expressing cells [27]. Moreover, while L5 D2expressing neurons in the mPFC principally project subcortically [62, 63], L5 D3-positive pyramidal neurons are a cortically projecting neuronal subtype [27]. Finally, D2expressing neurons are relatively more abundant in layers 2 and 3, while D3-positive neurons are relatively more abundant in layer 5 [27]. Thus, the reduced excitability of 
Fig. 5 Partial deletion of the D3 gene reverses the decreased excitability of pyramidal neurons, as well as the increased levels of DA in the $\mathrm{mPFC}$ of heterozygous Dys mutant mice. Representative traces (a) of neuronal firing recorded in mice with different genotypes. Pyramidal neurons of mPFC layer V were selected. Spikes were evoked in current-clamp configuration during depolarizing steps from 0 to 200 pA with $50 \mathrm{pA}$ intervals. Traces obtained during the 1-s depolarizing step at $150 \mathrm{pA}$ are shown. Summary of spike frequencies (b) obtained for different intervals of depolarizing steps in pyramidal neurons of mice with different genotypes: $\mathrm{D}^{+/+} \times \mathrm{Dys}^{+/+}(n=10) ; \mathrm{D}^{+/-} \times$ $\mathrm{Dys}^{+/+}(n=10) ; \mathrm{D}^{+/+} \times \mathrm{Dys}^{+/-}(n=13) ;$ and $\mathrm{D}^{+/-} \times \mathrm{Dys}^{+/-}(n=$ 11). Bar diagram showing the spike frequency (b) observed in mice with different genotypes, with a $150 \mathrm{pA}$ depolarizing step to highlight differences. Repeated measures ANOVAs revealed an intensity $\mathrm{x}$ genotype interaction $\left[F_{(9,120)}=3.254, P=0.0014\right]$ and intensity effect $\left[F_{(3,120)}=397.7, P<0.0001\right]$, as well as a genotype effect $\left[F_{(3,40)}=\right.$ 3.833, $P=0.0167]$. c Localization of the dialyzing portion of the probe within the $\mathrm{mPFC}$. The number represents the antero-posterior position of the slice (in $\mathrm{mm}$ ), relative to the bregma and basal extracellular DA levels in the mPFC of $\mathrm{D}^{+/+} \times \mathrm{Dys}^{+/+}(n=8), \mathrm{D}^{+/-} \times$ $\mathrm{Dys}^{+/+}(n=5), \mathrm{D}^{+/+} \times \mathrm{Dys}^{+/-}(n=7)$, and $\mathrm{D}^{+/-} \times \mathrm{Dys}^{+/-}(n=6)$ mice. One-way ANOVAs revealed a genotype effect $\left[F_{(3,21)}=3.997\right.$, $P=0.0213]$. Post hoc: $* P<0.05$ vs $\mathrm{D}^{+/+} \mathrm{Dys}^{+/+}$and ${ }^{\dagger} P<0.05$ vs $\mathrm{D}^{+/+} \mathrm{Dys}^{+/-}$. d Extracellular dopamine levels in the mPFC of $\mathrm{D}^{+/+} \times \mathrm{Dys}^{+/+}, \mathrm{D}^{+/-} \times \mathrm{Dys}^{+/+}, \mathrm{D}^{+/+} \times \mathrm{Dys}^{+/-} \mathrm{D}^{+/-} \times \mathrm{Dys}^{+/-}$ following chronic treatment (14 days) with risperidone (R) $\left[\mathrm{D} 3^{+/+} \times\right.$ $\mathrm{Dys}^{+/+}(n=7), \quad \mathrm{D}^{+/-} \times \mathrm{Dys}^{+/+} \quad(n=5), \quad \mathrm{D}^{+/+} \times \mathrm{Dys}^{+/-} \quad(n=$ $\left.5), \mathrm{D}^{+/-} \times \mathrm{Dys}^{+/-}(n=9)\right]$ or vehicle $(\mathrm{V})\left[\mathrm{D}^{+/+} \times \mathrm{Dys}^{+/+}(n=11)\right.$, $\mathrm{D}^{+/-} \times \mathrm{Dys}^{+/+}(n=5), \mathrm{D}^{+/+} \times \mathrm{Dys}^{+/-}(n=12), \mathrm{D}^{+/-} \times \mathrm{Dys}^{+/-}$ $(n=10)]$. Two-way ANOVAs revealed a genotype effect $\left[F_{(3,53)}=\right.$ 7.004, $P=0.0005]$. Post hoc: $* * P<0.01$ vs $\mathrm{D}^{+/+} \mathrm{Dys}^{+/+}$vehicletreated mice. e Quinpirole-induced dopamine release in the mPFC of $\mathrm{D}^{+/+} \times \mathrm{Dys}^{+/+}(n=10), \quad \mathrm{D}^{+/-} \times \mathrm{Dys}^{+/+}(n=5), \quad \mathrm{D}^{+/+} \times \mathrm{Dys}^{+/-}$ $(n=9), \mathrm{D}^{+/-} \times \mathrm{Dys}^{+/-}(n=12)$ following (14 days) with vehicle (V). Two-way ANOVAs treatment effect $\left.F_{(1,62)}=15.28 ; P=0.0002\right]$. Post hoc: $* P<0.05$ and $* * P<0.005$ vs baseline within each genotype group. f Quinpirole-induced dopamine release in the $\mathrm{mPFC}$ of $\mathrm{D}^{+/-} \times \mathrm{Dys}^{+/+}$(vehicle $n=5$, risperidone $n=5$ ) and $\mathbf{g ~ D} 3^{+/-} \times$ Dys $^{+/-}$(vehicle $n=12$, risperidone $n=9$ ) following chronic treatment (14 days) with risperidone or vehicle. Two-way ANOVAs revealed a treatment effect $\left[F_{(1,19)}=8.95, P=0.0075\right]$. Post hoc: at $40-\mathrm{min}$ $* * * P<0.001$ and $60-$ min $* * P<0.01$ vs $\mathrm{D}^{+/-} \times \mathrm{Dys}^{+-}$vehicletreated mice. Values are the means \pm s.e.m. $\mathrm{V}$ vehicle, $\mathrm{R}$ risperidone, $\mathrm{B}$ baseline, Q quinpirole, W washout

layer 5 pyramidal neurons, which we found in mice with Dys hypofunction, might be related to their increased D3 basal signaling. In support of this hypothesis, D3 hypofunction in Dys ${ }^{+/-}$mice ameliorated their altered excitability. In addition, postmortem studies revealed a twofold increase in the expression of D3 receptors in the brains of long-term hospitalized drug-free patients with schizophrenia [64], while patients with early psychosis displayed augmented levels of D3 receptor mRNA in T lymphocytes [65]. Thus, based on the present data, it is tempting to suggest that schizophrenia-related phenotypes are associated with a genetic background that increases relative D3 function. Therefore, selective blockade of D3 receptors might shift the D2/D3 balance to favor increased D2 expression, ultimately improving cognitive performance.
In conclusion, the present study supports D3 receptors as a valid target for improving psychiatric-related higher-order cognitive deficits. Furthermore, these new epistatic interactions might provide additional tools for improved stratification of patients with schizophrenia, which will be required for the application of a more personalized therapeutic approach.

Acknowledgements We thank Dr. M. Morini, D. Cantatore, R. Navone, G. Pruzzo, A. Parodi, B. Chiarenza, A. Monteforte, and C. Chiabrera for technical support. This work was supported by funding from the Istituto Italiano di Tecnologia, the University of Catania, the Brain and Behavior Research Foundation (2015 NARSAD 23234), and the Compagnia di San Paolo (2015-0321).

\section{Compliance with ethical standards}

Conflict of interest The authors declare that they have no conflict of interest.

Publisher's note: Springer Nature remains neutral with regard to jurisdictional claims in published maps and institutional affiliations.

\section{References}

1. Grace AA. Dysregulation of the dopamine system in the pathophysiology of schizophrenia and depression. Nat Rev Neurosci. 2016;17:524-32.

2. Schizophrenia Working Group of the Psychiatric Genomics C. Biological insights from 108 schizophrenia-associated genetic loci. Nature. 2014;511:421-7.

3. Weinstein JJ, Chohan MO, Slifstein M, Kegeles LS, Moore H, Abi-Dargham A. Pathway-specific dopamine abnormalities in schizophrenia. Biol Psychiatry. 2017;81:31-42.

4. Kellendonk C, Simpson EH, Polan HJ, Malleret G, Vronskaya S, Winiger $\mathrm{V}$, et al. Transient and selective overexpression of dopamine D2 receptors in the striatum causes persistent abnormalities in prefrontal cortex functioning. Neuron. 2006;49:603-15.

5. Amato D, Vernon AC, Papaleo F. Dopamine, the antipsychotic molecule: a perspective on mechanisms underlying antipsychotic response variability. Neurosci Biobehav Rev. 2018;85:146-59.

6. Thompson D, Whistler JL. Dopamine D(3) receptors are downregulated following heterologous endocytosis by a specific interaction with $\mathrm{G}$ protein-coupled receptor-associated sorting protein1. J Biol Chem. 2011;286:1598-608.

7. Bartlett SE, Enquist J, Hopf FW, Lee JH, Gladher F, Kharazia V, et al. Dopamine responsiveness is regulated by targeted sorting of D2 receptors. Proc Natl Acad Sci USA. 2005;102:11521-6.

8. Manago F, Mereu M, Mastwal S, Mastrogiacomo R, Scheggia D, Emanuele M, et al. Genetic disruption of Arc/Arg3.1 in mice causes alterations in dopamine and neurobehavioral phenotypes related to schizophrenia. Cell Rep. 2016;16:2116-28.

9. Miyakawa T, Sumiyoshi S, Deshimaru M, Suzuki T, Tomonari H. Electron microscopic study on schizophrenia. Mechanism of pathological changes. Acta Neuropathol. 1972;20:67-77.

10. Schubert KO, Focking M, Prehn JH, Cotter DR. Hypothesis review: are clathrin-mediated endocytosis and clathrin-dependent membrane and protein trafficking core pathophysiological processes in schizophrenia and bipolar disorder? Mol psychiatry. 2012;17:669-81.

11. Canfran-Duque A, Barrio LC, Lerma M, de la Pena G, Serna J, Pastor $\mathrm{O}$, et al. First-generation antipsychotic haloperidol alters 
the functionality of the late endosomal/lysosomal compartment in vitro. Int J Mol Sci. 2016;17:404.

12. Choi KH, Higgs BW, Weis S, Song J, Llenos IC, Dulay JR, et al. Effects of typical and atypical antipsychotic drugs on gene expression profiles in the liver of schizophrenia subjects. BMC psychiatry. 2009;9:57.

13. Heusler P, Newman-Tancredi A, Loock T, Cussac D. Antipsychotics differ in their ability to internalise human dopamine D2S and human serotonin 5-HT1A receptors in HEK293 cells. Eur J Pharmacol. 2008;581:37-46.

14. Lester HA, Miwa JM, Srinivasan R. Psychiatric drugs bind to classical targets within early exocytotic pathways: therapeutic effects. Biol psychiatry. 2012;72:907-15.

15. Tischbirek CH, Wenzel EM, Zheng F, Huth T, Amato D, Trapp S, et al. Use-dependent inhibition of synaptic transmission by the secretion of intravesicularly accumulated antipsychotic drugs. Neuron. 2012;74:830-44.

16. Ji Y, Yang F, Papaleo F, Wang HX, Gao WJ, Weinberger DR, et al. Role of dysbindin in dopamine receptor trafficking and cortical GABA function. Proc Natl Acad Sci USA. 2009;106:19593-8.

17. Talbot K, Ong WY, Blake DJ, Tang J, Louneva N, Carlson GC et al. Dysbindin-1 and its protein family. In: Javitt DC, Kantrowitz J, editors. Handbook of Neurochemistry and Molecular Neurobiology, 3rd edn, vol. 27. Springer Science: New York; 2009, p 107-241.

18. Scheggia D, Mastrogiacomo R, Mereu M, Sannino S, Straub RE, Armando M, et al. Variations in dysbindin-1 are associated with cognitive response to antipsychotic drug treatment. Nat Commun. 2018;9:2265.

19. Prats C, Arias B, Moya-Higueras J, Pomarol-Clotet E, Parellada M, Gonzalez-Pinto A, et al. Evidence of an epistatic effect between dysbindin-1 and neuritin-1 genes on the risk for schizophrenia spectrum disorders. Eur Psychiatry. 2017;40:60-64.

20. Papaleo F, Burdick MC, Callicott JH, Weinberger DR. Epistatic interaction between COMT and DTNBP1 modulates prefrontal function in mice and in humans. Mol Psychiatry. 2014;19:311-6.

21. Papaleo F, Weinberger DR. Dysbindin and schizophrenia: it's dopamine and glutamate all over again. Biol psychiatry. 2011;69:2-4.

22. Papaleo F, Yang F, Garcia S, Chen J, Lu B, Crawley JN, et al. Dysbindin-1 modulates prefrontal cortical activity and schizophrenia-like behaviors via dopamine/D2 pathways. Mol Psychiatry. 2012;17:85-98.

23. Sokoloff P, Le Foll B. The dopamine D3 receptor, a quarter century later. Eur J Neurosci. 2017;45:2-19.

24. Leggio GM, Bucolo C, Platania CB, Salomone S, Drago F. Current drug treatments targeting dopamine D3 receptor. Pharmacol Ther. 2016;165:164-77.

25. Gross G, Drescher K. The role of dopamine D(3) receptors in antipsychotic activity and cognitive functions. Handb Exp Pharmacol. 2012;213:167-210.

26. Nakajima S, Gerretsen P, Takeuchi H, Caravaggio F, Chow T, Le Foll B, et al. The potential role of dopamine D(3) receptor neurotransmission in cognition. Eur Neuropsychopharmacol. 2013; 23:799-813.

27. Clarkson RL, Liptak AT, Gee SM, Sohal VS, Bender KJ. D3 receptors regulate excitability in a unique class of prefrontal pyramidal cells. J Neurosci. 2017;37:5846-60.

28. Pich EM, Collo G. Pharmacological targeting of dopamine D3 receptors: possible clinical applications of selective drugs. Eur Neuropsychopharmacol. 2015;25:1437-47.

29. Maramai S, Gemma S, Brogi S, Campiani G, Butini S, Stark H, et al. Dopamine D3 receptor antagonists as potential therapeutics for the treatment of neurological diseases. Front Neurosci. 2016;10:451.

30. Stroup TS, McEvoy JP, Swartz MS, Byerly MJ, Glick ID, Canive $\mathrm{JM}$, et al. The National Institute of Mental Health Clinical
Antipsychotic Trials of Intervention Effectiveness (CATIE) project: schizophrenia trial design and protocol development. Schizophr Bull. 2003;29:15-31.

31. Keefe RS, Mohs RC, Bilder RM, Harvey PD, Green MF, Meltzer $\mathrm{HY}$, et al. Neurocognitive assessment in the Clinical Antipsychotic Trials of Intervention Effectiveness (CATIE) project schizophrenia trial: development, methodology, and rationale. Schizophr. 2003;29:45-55.

32. Ceaser AE, Goldberg TE, Egan MF, McMahon RP, Weinberger DR, Gold JM. Set-shifting ability and schizophrenia: a marker of clinical illness or an intermediate phenotype? Biol psychiatry. 2008;64:782-8.

33. Eling P, Derckx K, Maes R. On the historical and conceptual background of the Wisconsin Card Sorting Test. Brain Cognit. 2008;67:247-53.

34. Scheggia D, Bebensee A, Weinberger DR, Papaleo F. The ultimate intra-/extra-dimensional attentional set-shifting task for mice. Biol psychiatry. 2014;75:660-70.

35. Accili D, Fishburn CS, Drago J, Steiner H, Lachowicz JE, Park $\mathrm{BH}$, et al. A targeted mutation of the D3 dopamine receptor gene is associated with hyperactivity in mice. Proc Natl Acad Sci USA. 1996;93:1945-9.

36. Papaleo F, Lipska BK, Weinberger DR. Mouse models of genetic effects on cognition: relevance to schizophrenia. Neuropharmacology. 2012;62:1204-20.

37. Mereu M, Contarini G, Buonaguro EF, Latte G, Manago F, Iasevoli $\mathrm{F}$, et al. Dopamine transporter (DAT) genetic hypofunction in mice produces alterations consistent with ADHD but not schizophrenia or bipolar disorder. Neuropharmacology. 2017;121:179-94.

38. Torrisi SA, Salomone S, Geraci F, Caraci F, Bucolo C, Drago F, et al. Buspirone counteracts MK-801-induced schizophrenia-like phenotypes through dopamine D3 receptor blockade. Front Pharmacol. 2017;8:710.

39. Papaleo F, Crawley JN, Song J, Lipska BK, Pickel J, Weinberger $\mathrm{DR}$, et al. Genetic dissection of the role of catechol-Omethyltransferase in cognition and stress reactivity in mice. $\mathrm{J}$ Neurosci. 2008;28:8709-23.

40. Huang H, Michetti C, Busnelli M, Manago F, Sannino S, Scheggia D, et al. Chronic and acute intranasal oxytocin produce divergent social effects in mice. Neuropsychopharmacology. 2014;39:1102-14.

41. Scheggia D, Zamberletti E, Realini N, Mereu M, Contarini G, Ferretti $\mathrm{V}$ et al. Remote memories are enhanced by COMT activity through dysregulation of the endocannabinoid system in the prefrontal cortex. Mol Psychiatry. 2018;23:1040-50.

42. Lieberman JA, Stroup TS, McEvoy JP, Swartz MS, Rosenheck RA, Perkins DO, et al. Effectiveness of antipsychotic drugs in patients with chronic schizophrenia. N Engl J Med. 2005; 353:1209-23.

43. Jeanneteau F, Funalot B, Jankovic J, Deng H, Lagarde JP, Lucotte $\mathrm{G}$, et al. A functional variant of the dopamine D3 receptor is associated with risk and age-at-onset of essential tremor. Proc Natl Acad Sci USA. 2006;103:10753-8.

44. Papaleo F, Sannino S, Piras F, Spalletta G. Sex-dichotomous effects of functional COMT genetic variations on cognitive functions disappear after menopause in both health and schizophrenia. Eur Neuropsychopharmacol. 2015;25:2349-63.

45. Sannino S, Gozzi A, Cerasa A, Piras F, Scheggia D, Manago F, et al. COMT genetic reduction produces sexually divergent effects on cortical anatomy and working memory in mice and humans. Cereb Cortex. 2015;25:2529-41.

46. Lidow MS, Wang F, Cao Y, Goldman-Rakic PS. Layer V neurons bear the majority of mRNAs encoding the five distinct dopamine receptor subtypes in the primate prefrontal cortex. Synapse. 1998;28:10-20. 
47. Elvevag B, Goldberg TE. Cognitive impairment in schizophrenia is the core of the disorder. Crit Rev Neurobiol. 2000;14:1-21.

48. Vijayraghavan S, Wang M, Birnbaum SG, Williams GV, Arnsten AF. Inverted-U dopamine D1 receptor actions on prefrontal neurons engaged in working memory. Nat Neurosci. 2007;10:376-84.

49. Joyce JN, Millan MJ. Dopamine D3 receptor antagonists as therapeutic agents. Drug Discov today. 2005;10:917-25.

50. Hida H, Mouri A, Mori K, Matsumoto Y, Seki T, Taniguchi M, et al. Blonanserin ameliorates phencyclidine-induced visual-recognition memory deficits: the complex mechanism of blonanserin action involving D(3)-5-HT(2)A and D(1)-NMDA receptors in the mPFC. Neuropsychopharmacology. 2015;40:601-13.

51. Swerdlow NR. Update: studies of prepulse inhibition of startle, with particular relevance to the pathophysiology or treatment of Tourette Syndrome. Neurosci Biobehav Rev. 2013;37:1150-6.

52. Mohr D, Pilz PK, Plappert CF, Fendt M. Accumbal dopamine D2 receptors are important for sensorimotor gating in $\mathrm{C} 3 \mathrm{H}$ mice. Neuroreport. 2007;18:1493-7.

53. Braff DL, Geyer MA, Swerdlow NR. Human studies of prepulse inhibition of startle: normal subjects, patient groups, and pharmacological studies. Psychopharmacology. 2001;156:234-58.

54. Swerdlow NR, Light GA, Cadenhead KS, Sprock J, Hsieh MH, Braff DL. Startle gating deficits in a large cohort of patients with schizophrenia: relationship to medications, symptoms, neurocognition, and level of function. Arch Gen psychiatry. 2006; 63:1325-35.

55. Paylor R, Glaser B, Mupo A, Ataliotis P, Spencer C, Sobotka A, et al. Tbx1 haploinsufficiency is linked to behavioral disorders in mice and humans: implications for 22q11 deletion syndrome. Proc Natl Acad Sci USA. 2006;103:7729-34.

56. van den Buuse M. Modeling the positive symptoms of schizophrenia in genetically modified mice: pharmacology and methodology aspects. Schizophr. 2010;36:246-70.
57. Halberstadt AL, Geyer MA. Habituation and sensitization of acoustic startle: opposite influences of dopamine D1 and D2family receptors. Neurobiol Learn Mem. 2009;92:243-8.

58. Plappert CF, Pilz PK, Schnitzler HU. Factors governing prepulse inhibition and prepulse facilitation of the acoustic startle response in mice. Behav brain Res. 2004;152:403-12.

59. Winterer G, Weinberger DR. Genes, dopamine and cortical signal-to-noise ratio in schizophrenia. Trends Neurosci. 2004; 27:683-90.

60. Glickstein SB, Desteno DA, Hof PR, Schmauss C. Mice lacking dopamine D2 and D3 receptors exhibit differential activation of prefrontal cortical neurons during tasks requiring attention. Cereb cortex. 2005; 15:1016-24.

61. Schmieg N, Rocchi C, Romeo S, Maggio R, Millan MJ, Mannoury la Cour C. Dysbindin-1 modifies signaling and cellular localization of recombinant, human $\mathrm{D}(3)$ and $\mathrm{D}(2)$ receptors. $\mathrm{J}$ Neurochem. 2016;136:1037-51.

62. Dembrow NC, Chitwood RA, Johnston D. Projection-specific neuromodulation of medial prefrontal cortex neurons. J Neurosci. 2010;30:16922-37.

63. Gee S, Ellwood I, Patel T, Luongo F, Deisseroth K, Sohal VS. Synaptic activity unmasks dopamine D2 receptor modulation of a specific class of layer $\mathrm{V}$ pyramidal neurons in prefrontal cortex. $\mathrm{J}$ Neurosci. 2012;32:4959-71.

64. Gurevich EV, Bordelon Y, Shapiro RM, Arnold SE, Gur RE, Joyce JN. Mesolimbic dopamine D3 receptors and use of antipsychotics in patients with schizophrenia. A postmortem study. Arch Gen Psychiatry. 1997;54:225-32.

65. Cui Y, Prabhu V, Nguyen TB, Yadav BK, Chung YC. The mRNA expression status of dopamine receptor D2, dopamine receptor D3 and DARPP-32 in T lymphocytes of patients with early psychosis. Int J Mol Sci. 2015;16:26677-86. 